\title{
Non Alkolik Yağlı Karaciğer Hastalığı ile Yaş, Cinsiyet ve İnsülin Direnci İlişkisinin Araştırılması
}

\section{Investigation of the Relationship between Non-Alcoholic Fatty Liver Disease and Age, Gender and Insulin Resistance}

\author{
${ }^{1}$ Hayrullah YAZAR, ${ }^{1}$ Ömer Emre ÖZ, ${ }^{2}$ Elif KÖSE, ${ }^{3}$ Alper KARACAN, ${ }^{4}$ Mustafa YÖNTEM \\ 'Sakarya Üniversitesi Tıp Fakültesi Tıbbi Biyokimya AD., Sakarya, Türkiye \\ ${ }^{2}$ Sakarya Üniversitesi, Tıp fakültesi, Halk Sağlığı AD., Sakarya, Türkiye \\ ${ }^{3}$ Sakarya Üniversitesi Tıp Fakültesi Radyoloji AD., Sakarya, Türkiye \\ ${ }^{4}$ Necmettin Erbakan Üniversitesi Fen Fakültesi Biyoteknoloji Bölümü, Konya, Türkiye
}

Hayrullah Yazar: https://orcid.org/0000-0001-9447-6322

Ömer Emre Öz: https://orcid.org/0000-0002-7662-5061

Elif Köse: https://orcid.org/0000-0002-2232-4538

Alper Karacan: https://orcid.org/0000-0001-8930-9546

Mustafa Yöntem: https://orcid.org/0000-0001-9350-8708

\section{ÖZ}

Amaç: Bu çalışmada non-alkolik yağlı karaciğer hastalarında (NAYKH) insülin direnci, yaş ve cinsiyet ilişkisinin araştırılması amaçlanmıştır.

Materyal ve Metot: NAYKH tanılı alkol kullanmayan hastalara ait veriler, bir y1l boyunca kayıt altına alındı. Hastaların NAYKH tanıs1 4D ultrason cihazı ile konuldu. Çalışmada tüm hastaların açlık kan şekeri ve açlık insülin hormonu değerleri kullanılarak, insülin dirençleri hesaplandı. Elde edilen verilerin istatistiği "IBM SPSS for Windows Version 20.0 software" programı ile yapıld 1 ve anlamlılık düzeyi $\mathrm{p}<0,05$ kabul edildi.

Bulgular: Çalışmada; kriterlere uyan 312 erkek ve 558 kadın, toplamda 870 hasta incelendi. Erkeklerde yaş ortalamas1 15, kadınlarda 29 bulundu ve bu farkın anlaml olduğu görüldü. NAYKH görülme sıklığ1; erkeklerde \% 47,75 iken, kadınlarda \%33,51 oldu. Yaşa göre NAYKH; çocuklarda \%32,57 iken, erişkinlerde \%49,28 şeklinde idi. HOMA-IR ortalama değerleri cinsiyete göre; erkeklerde 2,51 ve kadınlarda 2,53 idi. Yaşa göre HOMA-IR ortalama değerleri; çocuklarda 3,14 ve erişkinlerde 2,09 bulundu. HOMA-IR grade guplarına göre incelenince, bu değerlerin grade II ve grade III'te anlamlı olarak arttığı görüldü. Sonuç: NAYKH, yaş ve cinsiyet arasında ilişki vardır. Şöyle ki; erkeklerde bu hastalık hem sık görülmekte hem de erken yaşta ortaya çıkmaktadır. İlaveten; HOMAIR'nin çocuklarda daha yüksek çıkması, üzerinde daha geniş çaplı araştırma yapılması gereken bir sonuç olarak görüldü.

Anahtar Kelimeler: Cinsiyet, HOMA-IR, NAYKH, 4D ultrason, yaş

\section{ABSTRACT}

Objective: In the study, it was aimed to investigate of insulin resistance, age, and gender relationship in nonalcoholic fatty liver disease (NAFLD).

Materials and Methods: The data of patients diagnosed with NAFLD who did not drink alcohol were recorded for one year. The patients were diagnosed with NAFLD with Doppler USG and divided into three groups. In the study, insulin resistance was calculated using fasting blood glucose and fasting insulin hormone values of all patients. The statistics of the obtained data were made using the program "IBM SPSS for Windows Version 20.0" and the significance level was accepted as $\mathrm{p}<0.05$.

Results: In the study; A total of 870 patients, 312 males and 558 females, who met the criteria were examined. The average age was 15 for males and 29 for females, and this difference was found to be significant. Incidence of NAFLD; While it was $47.75 \%$ for men, it was $33.51 \%$ for women. NAFLD by age; While it was $32.57 \%$ in children, it was $49.28 \%$ in adults. HOMA-IR average values; 2.51 in male patients and 2.53 in women. HOMA-IR average values by age; 3.14 in children and 2.09 in adults. When the HOMA-IR values were examined according to the grade groups, it was seen that these values increased significantly in grade II and grade III.

Conclusion: There is a relationship between NAFLD, age and gender. Namely, This disease is common in men and occurs at an early age. Additionally, the higher HOMA-IR in children was seen as a result that should be researched more widely.

Keywords: Age, gender, HOMA-IR, NAYKH, 4D ultrasound

\section{Yayın Bilgisi / Article Info:}

Gönderi Tarihi/ Received: 23/03/2021

Kabul Tarihi/ Accepted: 01/04/2021

Online Yayın Tarihi/ Published: 05/06/2021

Sakarya Üniversitesi Tıp Fakültesi Tıbbi Biyokimya AD., Sakarya, Türkiye

Tel: +90 5323179702

E-mail: drhyazar@hotmail.com 


\section{GÍRIŞ}

Karaciğer yağlanması ilk defa Mayo Klinik'ten Ludwig ve arkadaşlarının çalışmalarıyla, 1980 yılında bir hastalık olarak ele alındı. Akabinde; alkol kullanmamış olmasına rağmen karaciğer fonksiyon testleri yüksek olan ve histopatolojik olarak alkole bağlı karaciğer hastalığında görülen bulguları içeren bir hastalık tablosu tespit edilmiş ve non-alkolik steatohepatit (NASH) olarak isimlendirilmiştir. ${ }^{1}$ İleriki zamanlarda bu kavram yerini, non-alkolik yağlı karaciğer hastalığına (NAYKH) bırakmıştır. ${ }^{2}$

NAYKH literatürde yerini aldıktan sonra yapılan araştırmalar gösterdi ki, bu hastalığın görülme sıklığı giderek artmaktadır. $\mathrm{Bu}$ artışta metabolik sendromun etkisi muhtemeldir. Dünya Sağlık Örgütü (DSÖ) tarafından, uluslararası derneklerin kılavuzları kullanılarak metabolik sendrom için beş farklı risk faktörü tanımlandı. ${ }^{3} \mathrm{Bu}$ risk faktörlerinden insülin direnci NAYKH'da önemli bir yere sahiptir. İnsülin direncinin metabolik sendrom başta olmak üzere pek çok hastalıkla ilişkilendirilmesi, yeni tanımlamaları beraberinde getirdi. Bunlar arasında insülin direnci (HOMA-IR: Homeostatic Model Assesment Insulin Resistant), üzerinde en çok araştırma yapılan index olarak göze çarpmaktadır. ${ }^{4-8}$ HOMA-IR; hastadan alınan kan serumundan elde edilen açlık glukoz ve insülin değerlerinin kullanımı ile beta sekresyon fonksiyonunu ve insülin direncini değerlendirebilen, geniş hasta populasyonlarını pratik inceleyen hesaplama yöntemidir. ${ }^{9}$ HOMA-IR indeksi, günümüzde pek çok laboratuvar tarafından otomasyon sistemine doğrudan yansitılmaktadır. Bu durum; klinisyenler için insülin direnci tanı ve tedavisinde, özellikle metabolik hastalıklara giden sürecin erken tespitinde, büyük kolaylık sağlamaktadır. Ancak, HOMA-IR farkındalığının hekimlerde yeterince yüksek olduğunu söylemek için erkendir. Nitekim, klinisyenlerin HOMA-IR kullanım oranları düşüklüğü bu görüşü destekler niteliktedir. ${ }^{10}$ Öte yandan; son y1llarda hastalık ve hastaya yaklaşım konusunda yeni tanımlamalar yapılması ise, olumlu bir gelişme olarak dikkat çekici görülmektedir. ${ }^{11}$

$\mathrm{Bu}$ çalışmada non alkolik yağlı karaciğer hastalığı ile yaş, cinsiyet ve insülin direnci arasındaki ilişkiyi ortaya koymak amaçlanmıştır.

\section{MATERYAL VE METOT}

Bu çalışma için Sakarya Üniversitesi Tıp Fakültesi Girişimsel olmayan Etik Kurulundan izin alınmıştır (Tarih: 28.6.2015, karar no: 115). Çalışmamız uluslararası bildirgelerde ön görülen kriterlere göre yapıl- miştır.

Yapılan çalışmada; dahil edilme kriterlerine uyan hastaların verileri, bir yıllık zaman diliminde, biyokimya laboratuvarı ve radyoloji kliniğinde hastane bilgi yönetim sistemi (hbys) üzerinden incelendi. Hastaların dahil edilme kriterleri; alkol kullanmamak, doppler USG ile karaciğer yağlanması tanısı konulmuş olmak ve kronik hastalığı olmamak (hepatit, otoimmün hastalıklar) şeklinde belirlendi. Ayrıca; kanser tanılı olmak, çalışmadan çıkartılma gerekçesi olarak kabul edildi. Viral hepatitleri dışlamak için tüm hastaların HbsAg ve anti $\mathrm{HCV}$ markerları incelendi. Doppler ultrason ile yapılan değerlendirmede; karaciğerde tümör, kist gibi yer kaplayıcı kitle olan hastalar çalışmadan çıkartıldı. Çalışmada, hasta serumlarından hormon (insülin) ve açlık kan şekeri (AKŞ), alanin aminotransferaz (ALT) ve aspartat aminotransferaz (AST) sirasiyla; Architect i2000 cihazında ve Architect C16000 cihazında çalışıldı. Hastaların karaciğer görüntüleme işlemi radyoloji kliniğinde 4D USG ile uzman doktorlar tarafından yapıldı ve yağlanma düzeyleri güncel literatüre göre sinıflandırıldı. ${ }^{12}$ Karaciğer yağlanması, Grade I: hafif ekojenite artışı, diyafram ve intrahepatitk damarların duvarları normal görünümde, Grade II: orta derecede ekojenite artışı, diyafram ve intrahepatik damar duvarları görüntüsünde hafif silinme mevcut, Grade III: belirgin eko artışı, diyafram, intrahepatik damar duvarları ve sağ lob posterioru görüntüsünde ileri derecede veya tamamen silinmiş, şeklinde derecelendirildi.

Istatistiksel Analizler: Değişkenlerin normal dağıl1ma uygunluğu görsel ve analitik yöntemlerle incelendi ve tanımlayıcı analizlerde normal dağılan değişkenler için aritmetik ortalama, standart sapma hesapland1. Normal dağılmayan değişkenler için ise ortanca ve çeyrekler arası genişlik kullanıldı. Kategorik değişkenler sayı (n) ve yüzdelerle (\%) belirtildi. Sürekli değişkenlerde grupların ortalamaları arasındaki farkın anlamlılığını değerlendirmede normal dağılım göstermeyen gruplarda Mann Whitney-U testi, normal dağılım gösteren gruplarda ise bağımsız gruplarda T testi kullanıldı. Kategorik değişkenler arasında ki farkın anlamlılığını tespit etmek için pearson kikare testi kullanıldı. Normal dağılım göstermeyen üç yada daha fazla grubun ortalamaları arasındaki farkın anlamlılığını test etmek için Kruskal Wallis testi kullanıldı. Tüm istatistik çalışmaları "IBM SPSS for Windows Version 20.0 software" programı kullanılarak yapıld1. İstatistiksel anlamlılık düzeyi $\mathrm{p}<0,05$ olarak kabul edildi. 


\section{BULGULAR}

Araştırmaya dahil edilen hasta sayısı toplamda 870 olup, bu kişilerin; 396'sı 18 yaş altında, 474'ü ise 18 yaş ve üzerinde idi. Yine katılanların 312'si erkek (\% $35,86), 558$ 'i ise kadın $(\% 64,13)$ idi. Tablo 1 'de yaş ve cinsiyet birlikte değerlendirilince; erkek hastaların yaş ortalaması 15 , kadın hastaların ise 29 olduğu ve bu farkın anlamlı olduğu görüldü $(p<0,001)$. Tablo 2'de gösterildiği gibi, yapılan Ki kare testi ve Student $\mathrm{T}$ testine göre; erişkinlerde karaciğer yağlanması ve ALT, AST yüksekliği, çocuklara göre anlamlı derecede yüksek bulundu $(\mathrm{p}<0,05)$.

Doppler USG ile yapılan incelemeye göre; NAYKH erkeklerde $\% 47,6$ ve kadınlarda $\% 33,5$ olarak tespit edildi. Erkeklerde görülen bu artışın istatistiksel olarak da anlamlı olduğu görüldü $(p<0,001)$. Bu duruma paralel olarak ALT ve AST erkelerde, kadınlardan anlamlı derecede yüksek çıktı (Tablo 3).

HOMA-IR değerleri cinsiyet açısından incelendiği zaman; 312 erkek hastanın ortalaması 2,51 iken, 558 kadın hastanın ortalama değeri 2,53 olarak bulundu. Yapılan Mann Whitney U Testine göre; HOMAIR'de cinsiyete göre istatistiksel açıdan anlamlı bir farklı1lı olmadığ görüldü $(\mathrm{p}>0,05)$. Yaşa göre HOMA-IR değerleri karşllaştırılınca; 396 çocuğun ortalama değeri 3,14 iken, 474 erişkinin ortalama değeri 2,09 bulundu. HOMA-IR'nin çocuklarda erişkinlerden yüksek bulunması dikkat çekici görüldü. HOMA-IR değerleri grade guplarına göre incelenirse, bu değerlerin grade II ve grade III'te anlamlı olarak arttığı görüldü (Șekil 1). Yapılan Kruskal Wallis testinde ise, gradeII ve grade III'te, ALT ve AST yüksekliğinin anlamlı olduğu görüldü (Tablo 4). Bu durum, karaciğerde yağlanma artışı ile ALT ve AST artı̧ıının parelel olabileceğini gösterdi.

\section{TARTIŞMA VE SONUÇ}

Karaciğer yağlanması; trigliserit oranın karaciğer ağırlığının yüzde 5 'in üstüne çıkması veya histopatolojik araştırmalarda hepatositlerdeki yağ vakuollerinin yüzde 5'ten fazla olması şeklinde tanımlanmıştır. NAYKH ise; yaygınlığ 1 , karmaşık patogenezi ve onaylanmış tedavilerin olmaması nedeniyle, büyük bir zorluk olarak ortaya çıkmıştır. ${ }^{13} \mathrm{Bi}$ zim çalışmamızda sadece NAYKH değil; aynı zamanda metabolik sendromun önemli bir ögesi olan insülin direnci, yaş ve cinsiyet göz ardı edilmeksizin incelenmiştir. Araştırmacılar önümüzdeki on yıl içinde NAYKH' da görülen bu artışın devam etmesi halinde, karaciğer transplantasyonu için önde gelen endikasyon haline gelebileceğini belirtmektedirler. ${ }^{13}$
NAYKH prevelans artısııın, obezite ve tip II diyabetes mellitus artışları ile orantılı olduğu ifade edilmektedir. Öte yandan, NAYKH tedavi ve önleme yöntemleri için, araştırıcıların non-invaziv prognostik biyobelirteçler bulma çabaları da devam etmektedir. ${ }^{14} \mathrm{NAYKH}$ ve HOMA-IR değerleri arasındaki ilişkiyi gösteren bir başka çalışmada ise, NAYKH olan hastaların \%83-98'inde HOMA-IR değerlerinin daha yüksek olduğu gösterilmiştir. ${ }^{15}$ Bizim çalışmamızda NAYKH derecesinde artış olan grade II ve grade III'te, HOMA-IR'nin daha yüksek çıkması da bu araştırmalar ile örtüşmektedir.

NAYKH'nın obeziteyle ilişkisi ve diyetle yağ alımı ile bağlantılı olduğu, araştırmacılar tarafindan dile getirilen bir başka konudur. ${ }^{16}$ Yine onlara göre; NAYKH'da, hem artan serbest yağ asitleri hem de denovo hepatik lipogenez nedeniyle, hepatositte aşırı trigliserit birikimi görülmektedir. Sonuçta, hepatik steatoz gelişimi karşımıza çıkmaktadır. Araştırmacılar, NAYKH'nin lipotoksisite ile ilişkili mekanizmasının, "çift vuruş" hipotezi ile açıklanabileceğini belirtmektedirler. ${ }^{16}$ Burada; insülin direnci, NAYKH gelişimi ve ilerlemesindeki ana mekanizma olarak ileri sürülmektedir. Ortaya çıkan metabolik oksidatif stresin, otofaji ve inflamasyon ile NAYKH ilerlemesine neden olduğu ifade edilmektedir. ${ }^{16}$ Araştırıcılara göre, kadınlarda NAYKH'nın erkeklere göre daha az görülmesi, menapoz sonrasinda ortadan kalmaktadır. Bu yüzden, kadınlara östrojen takviyesi önerilmiş ve teorik olarak NAYKH gelişmesi ve ilerlemesini azaltabilir denilmiştir. ${ }^{17}$ Ancak, yine aynı araştırmacılar tarafından, "farklı hormonların değişken etkisi de dikkatlice düşünülmelidir" uyarısı yapılmıştır. ${ }^{17} \mathrm{Ça}$ lışmamızda da NAYKH görülme sıklığı, kadınlarda erkeklere göre anlamlı derece de düşük çıkmıştı. Kanaatimize göre; araştırmamıza katılan kadınların yaş ortalamasının düşüklüğü burada belirleyici olmuştur. Sonuç olarak yapılan çalışmamızdan elde edilen verilere göre; NAYKH, yaş ve cinsiyet arasında ilişki olduğu görülmektedir. Şöyle ki; menapoza girmemiş genç kadınlarda NAYKH görülme sıklığı erkeklere göre anlamlı derecede azdır. Erkeklerde bu hastalık hem sık görülmekte hem de erken yaşta ortaya çıkmaktadır Sonuçlar yaş açısından değerlendirilince HOMA-IR, çocuklarda daha yüksek çıkmaktadır. Hiç kuşkusuz bu yükseklik, üzerinde daha geniş araştırmalar yapılması gereken bir sonuçtur, zira; yaygınlaşan obezite salgınının, çocukları ne kadar etkilediğini gösteren bir bulgu olması muhtemeldir. Çalışmanın bir başka dikkat çekici sonucu ise; hem HOMA-IR yüksekliğinin hem de ALT ve AST yüksekliğinin, 4D USG ile yapılan NAYKH derecelendirmesi ile 
paralellik içermesidir. Bu durum; NAYKH tanısı için, insülin direnci ve karaciğer enzim yüksekliğinin, prognostik biyobelirteçlerden olabileceğini göstermesi açısından önemli görülmüştür.

Etik Komite Onayı: Bu çalışma için Sakarya Üniversitesi Tıp Fakültesi Girişimsel olmayan Etik Kurulundan izin alınmıştır (Tarih:28.6.2015, karar no: 115).

Çıkar Çatışması: Yazarlar çıkar çatışması bildirmemektedir.

Yazar Katkılart: Fikir - HY, ÖEÖ; Denetim - HY; Malzemeler - HY, AK; Veri Toplanması ve/veya İşleme - ÖEÖ, AK; Analiz ve/veya Yorum - HY, ÖEÖ, EK, MY; Yazıyı yazan - HY, ÖEÖ.

Hakem değerlendirmesi: Dış bağımsız.

\section{KAYNAKLAR}

1. Ludwig J, Viggiano TR, McGill DB, Oh BJ. Nonalcoholic steatohepatitis: Mayo Clinic experiences with a hitherto unnamed disease. Mayo Clin Proc. 1980;55(7):434-438.

2. McCullough A, Bugianesi E, Marchesini G, Kalhan SC. Gender dependent alterations in serum leptin in alcoholic cirrhosis. Gastroenterology. 1998;115:947-953.

3. National Cholesterol Education Program (NCEP) Expert Panel on Detection, Evaluation, and Treatment of High Blood Cholesterol in Adults (Adult Treatment Panel III). Third Report of the National Cholesterol Education Program (NCEP) Expert Panel on Detection, Evaluation, and Treatment of High Blood Cholesterol in Adults (Adult Treatment Panel III) final report. Circulation. 2002;106 (25):3143-421.

4. Wenclewska S, Szymczak-Pajor I, Drzewoski J, Bunk M, Śliwińska A. Vitamin D Supplementation Reduces Both Oxidative DNA Damage and Insulin Resistance in the Elderly with metabolic disorders. Int J Mol Sci. 2019;20(12):2891. doi:10.3390/ijms20122891

5. Chacińska M, Zabielski P, Książek M, et al. The Impact of OMEGA-3 fatty acids supplementation on insulin resistance and content of adipocytokines and biologically active lipids in adipose tissue of high-fat diet fed rats. Nutrients. 2019;11 (4):835. doi:10.3390/nu11040835

6. Can M, Duran C, Guney I, Elmas H, Ayhan M, Erdem SS. The relationship between glomerular filtration rate, and metabolic and inflammatory parameters in obese and non-obese patients with polycystic ovary syndrome. Clin Investig Arterio- scler. 2020;32(6):256-262. doi:10.1016/ j.arteri.2020.04.003

7. Şendur R, Özcabı B, Mutlu GY, Bozaykut A. Effective sociodemographic and clinical factors in weight loss in childhood obesity. Turk Pediatri Ars. 2018;53(3):169-176. doi:10.5152/ TurkPediatriArs.2018.6210

8. Elmaogullari S, Demirel F, Hatipoglu N. Risk factors that affect metabolic health status in obese children. J Pediatr Endocrinol Metab. 2017;30 (1):49-55. doi:10.1515/jpem-2016-0128

9. Matthews DR, Hosker JP, Rudenski AS, Naylor BA, Treacher DF, Turner RC. Homeostasis model assessment: insulin resistance and beta-cell function from fasting plasma glucose and insulin concentrations in man. Diabetologia. 1985;28(7):4129.

10. Yazar H, Öz OE, Köse E. Biyokimya laboratuvarında yeni uygulamalar ve klinisyenlerin farkındalığı. Online Türk Sağlık Bilimleri Dergisi. 2019;4(2):170-182. doi:10.26453/otjhs.459641

11. Yazar H, Yılmaz ZM, Yıldırım K, Yazar EF, Yazar İO. Systematic perspectives in medicine; halal life medicine, functional medicine, holistic medicine, lifestyle medicine. Journal of Halal Life Medicine. 2019;1(1):01-19.

12. Carol M. Rumack, Stephanie R, et.al. Diagnostic Ultrasound. Volume 1 3nd ed. Missouri, St.Louis: Elsevier Mosby. An Affiliate of Elsevier Press; 2005.

13. Neuschwander-Tetri BA. Non-alcoholic fatty liver disease. BMC Med. 2017;15(1):45. doi:10.1186/s12916-017-0806-8

14. Younossi ZM. Non-alcoholic fatty liver disease A global public health perspective. J Hepatol. 2019;70(3):531-544.

15. Bhat G, Baba CS, Pandey A, Kumari N, Choudhuri G. Life style modification improves insulin resistance and liver histology in patients with nonalcoholic fatty liver disease. World J Hepatol. 2012;4(7):209-217. doi:10.4254/wjh.v4.i7.209

16. Engin A. Non-alcoholic fatty liver disease. Adv Exp Med Biol. 2017;960:443-467.

17. Ballestri S, Nascimbeni F, Baldelli E, Marrazzo A, Romagnoli D, Lonardo A. NAFLD as a sexual dimorphic disease: role of gender and reproductive status in the development and progression of nonalcoholic fatty liver disease and inherent cardiovascular risk. Adv Ther. 2017;34(6):12911326. doi:10.1007/s12325-017-0556-1 
Tablo 1. Araştırmaya katılanların yaş ve cinsiyet değerlendirmesi.

\begin{tabular}{|c|c|c|c|c|c|}
\hline \multirow[t]{2}{*}{ Özellikler } & \multicolumn{2}{|c|}{ Erkek } & \multicolumn{2}{|c|}{ Kadın } & \multirow[b]{2}{*}{$\mathbf{p}$} \\
\hline & Sayı & Yüzde & Sayı & Yüzde & \\
\hline \multirow[t]{2}{*}{ Yaş } & $n=312$ & 35,8 & $\mathrm{n}=558$ & 64,13 & \multirow[t]{2}{*}{$<0,001 *$} \\
\hline & $\begin{array}{r}\text { Ortalama- } \\
\text { Or } \\
\text { En küçük }\end{array}$ & $\begin{array}{l}5,9 \pm 20,42 \\
15 \\
\text { yük }=0-77\end{array}$ & $\begin{array}{l}\text { Ortalam } \\
\text { En küç }\end{array}$ & $\begin{array}{l}558 \\
=31,0 \pm 19,921 \\
\text { ca }=29 \\
\text { büyük }=0-90\end{array}$ & \\
\hline
\end{tabular}

*: Student T Testi; Grupların yaş değerleri ortalama \pm standart sapma şeklinde gösterilmiştir. 
Tablo 2. NAYKH ve serum ALT, AST değerlerinin yaşa göre incelenmesi.

\begin{tabular}{|c|c|c|c|c|c|}
\hline \multirow[t]{2}{*}{ Özellikler } & \multicolumn{2}{|c|}{ Çocuk } & \multicolumn{2}{|c|}{ Erișkin } & \multirow[b]{2}{*}{$\mathbf{P}$} \\
\hline & Say1 & Yüzde & Say1 & Yüzde & \\
\hline $\begin{array}{l}\text { NAYKH } \\
\text { Var } \\
\text { Yok }\end{array}$ & $\begin{array}{c}\mathrm{n}=396 \\
129 \\
267\end{array}$ & $\begin{array}{l}32,6 \\
67,4\end{array}$ & $\begin{array}{c}\mathrm{n}=474 \\
207 \\
267\end{array}$ & $\begin{array}{l}43,7 \\
56,3\end{array}$ & $0,001 *$ \\
\hline ALT & $\begin{array}{r}\text { Ortalama } \\
\text { Ort } \\
\text { En küçük }\end{array}$ & $\begin{array}{r}=16,93 \\
6-155 \\
\end{array}$ & $\begin{array}{l}\text { Ortalam: } \\
\text { En küçü }\end{array}$ & $\begin{array}{l}3 \pm 28,16 \\
=6-227\end{array}$ & $0,001 * *$ \\
\hline AST & $\begin{array}{l}\text { Ortalama } \\
\text { Ort } \\
\text { En küçük- }\end{array}$ & $\begin{array}{l}15,77 \\
10-148 \\
\end{array}$ & $\begin{array}{l}\text { Ortalam } \\
\text { En küçü }\end{array}$ & $\begin{array}{l} \pm 15,31 \\
=7-139\end{array}$ & $0,022 * *$ \\
\hline
\end{tabular}

*: Ki kare Testi; **: Student T Testi; NAYKH: Non alkolik yağlı karaciğer hastalı̆̆ı, ALT: Alanin aminotransferaz, AST: Aspartat aminotransferaz. Grupların ALT, AST değerleri ortalama \pm standart sapma şeklinde gösterilmiştir. 
Tablo 3. NAYKH ve serum ALT, AST değerlerinin cinsiyete göre incelenmesi.

\begin{tabular}{|c|c|c|c|c|c|}
\hline \multirow[t]{2}{*}{ Özellikler } & \multicolumn{2}{|c|}{ Erkek } & \multicolumn{2}{|c|}{ Kadın } & \multirow[t]{2}{*}{$\mathbf{P}$} \\
\hline & Sayı & Yüzde & Sayı & Yüzde & \\
\hline $\begin{array}{l}\text { NAYKH } \\
\text { Var } \\
\text { Yok }\end{array}$ & $\begin{array}{c}\mathrm{n}=312 \\
149 \\
164\end{array}$ & $\begin{array}{l}47,6 \\
52,4\end{array}$ & $\begin{array}{c}\mathrm{n}=558 \\
187 \\
371\end{array}$ & $\begin{array}{l}33,5 \\
66,5\end{array}$ & $<0,001^{*}$ \\
\hline ALT & $\begin{array}{l}\text { Ortalam } \\
\text { En küçü }\end{array}$ & $\begin{array}{l}7 \\
23,1 \pm 15,31 \\
19,0 \\
\text { iyük=7-139 }\end{array}$ & $\begin{array}{r}\text { Ortalama } \\
\text { Or } \\
\text { En küçük }\end{array}$ & $\begin{array}{l}98 \pm 21,62 \\
7,0 \\
\text { ük }=6-227\end{array}$ & $<0,001 * *$ \\
\hline AST & $\begin{array}{l}\text { Ortalam } \\
\text { En küçül }\end{array}$ & $\begin{array}{l}9 \\
8,53 \pm 16,12 \\
24,0 \\
\text { yük }=10-148\end{array}$ & $\begin{array}{r}\text { Ortalama } \\
\text { Or } \\
\text { En küçük }\end{array}$ & $\begin{array}{l}03 \pm 14,79 \\
8,0 \\
u ̈ k=7-149\end{array}$ & $<0,001 * *$ \\
\hline
\end{tabular}

*: Ki kare Testi; **Mann Whitney U Testi; NAYKH: Non alkolik yağlı karaciğer hastalı̆̆ı, ALT: Alanin aminotransferaz, AST: Aspartat aminotransferaz. 
Tablo 4. NAYKH ve ALT, AST değerlerinin karşılaştırması.

\begin{tabular}{|c|c|c|c|}
\hline \multicolumn{4}{|l|}{ ALT } \\
\hline NAYKH & $\mathrm{n}=799$ & Ortanca & $\mathbf{P}^{*}$ \\
\hline Grade 0 & 492 & 17,0 & \multirow[t]{4}{*}{$<0,001$} \\
\hline Grade 1 & 168 & 20,5 & \\
\hline Grade 2 & 117 & 32,0 & \\
\hline Grade 3 & 22 & 45,5 & \\
\hline \multicolumn{4}{|c|}{$\mathbf{A S T n}=788$} \\
\hline Grade 0 & 494 & 20,0 & \multirow[t]{4}{*}{$<0,001$} \\
\hline Grade 1 & 166 & 19,5 & \\
\hline Grade 2 & 112 & 23,0 & \\
\hline Grade 3 & 16 & 26,5 & \\
\hline
\end{tabular}

*: Kruskal Wallis Testi; NAYKH: Non alkolik yağlı karaciğer hastalığı; ALT: Alanin aminotransferaz; AST: Aspartat aminotransferaz. 


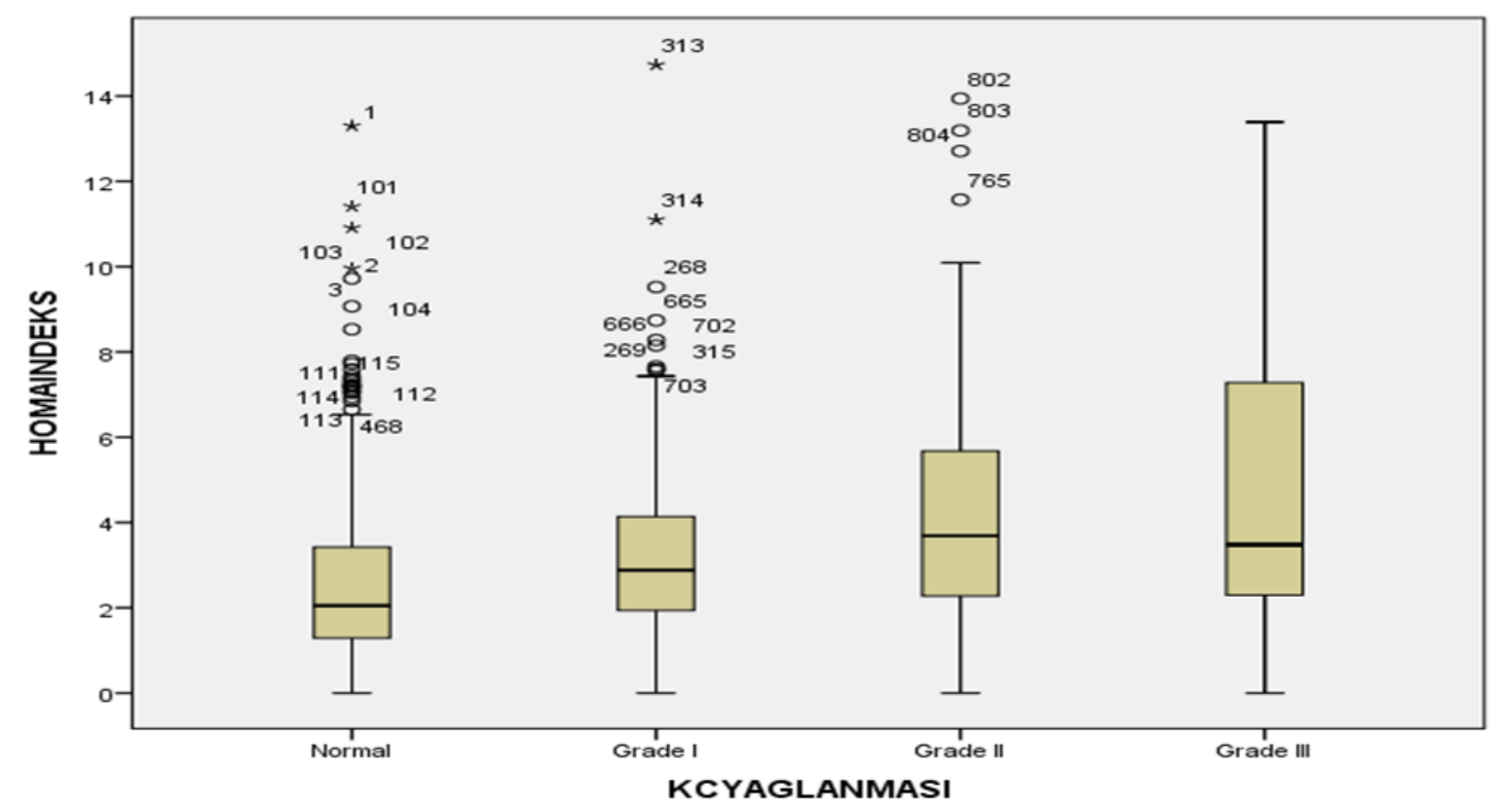

Şekil 1. Hepatik USG ile saptanan karaciğer yağlanma dereceleri ve HOMA-IR karşılaştırması. 